\title{
O papel dos
}

\section{cronistas}

\section{brasileiros na}

transformação da imagem da

\section{capoeira no início do século $X X$}

\section{Pedro Gabriel Neves de} Aquino*

DOI: 10.11606/issn.2318-8855.v10i1p331-359

Resumo: o objetivo deste artigo é analisar como os cronistas brasileiros do início do século XX constroem uma nova imagem sobre a capoeira para a sociedade brasileira entre os anos 1900 e 1930, valorizando-a enquanto esporte em contraposição à imagem negativa que existia previamente sobre a prática, marcada por ideias do racismo científico. Buscando compreender isso, será realizada a análise de crônicas, artigos e guias esportivos produzidos por intelectuais do período, visando expor os argumentos destes intelectuais que buscaram a valorização da capoeira, expondo as transformações que ocorreram no pensamento social brasileiro sobre a prática da capoeira no período, perpassando questões como a manifestação ou apagamento da herança negra da capoeira.

Além disso, a análise busca entender como a capoeira se insere e quais debates apareceram ligados a ela na construção da nacionalidade republicana brasileira em uma sociedade pós-abolição da escravidão marcada por teorias de superioridade racial e as principais disputas argumentativas nesse meio intelectual entre cronistas, jornalistas e folcloristas). Essa construção da imagem da capoeira com valor e destaque na sociedade teve grande influência na formação das primeiras academias formais de capoeira (1932), a descriminalização da prática por Vargas (1936 oficialmente), seu subsequente reconhecimento como prática esportiva nacional do Brasil e sua posterior difusão pelo mundo, marcando fortemente o entendimento de nacionalidade do povo brasileiro. Assim, entender a forma como os círculos letrados do Brasil reconstroem a imagem da capoeira é buscar compreender uma parte da formação da nacionalidade do Brasil.

Palavras-chaves: capoeira, nacionalidade brasileira, intelectuais, esporte. 


\section{artigos}

O papel dos cronistas brasileiros na transformação da imagem da capoeira no início do século XX (1900-1930) Introdução e contexto do pensamento social brasileiro do início do século XX

Historicamente, a capoeira foi atividade das camadas marginalizadas da sociedade brasileira. Apesar de não haver consenso sobre a origem da prática, existem registros referentes a presença da capoeira no final do século XVIII no Rio de Janeiro que apontam sua prática por escravizados e a repressão da capoeira por parte das autoridades, sendo assim uma atividade duplamente marginal, tanto por ser perseguida pelo estado quanto por estar atrelada a grupos marginais daquela sociedade. Apesar de sua marginalização histórica, a capoeira no Rio de Janeiro persistiu durante o final do período colonial e todo o imperial, aparecendo registros de sua prática também em outras grandes cidades do país no período, como o Recife. Essa perseguição contra a prática acontecia tanto pela sociedade civil, que considerava a atividade e seus praticantes vadios, criminosos, quanto por aparatos do Estado, como a polícia (Guarda Nacional na época) que encarcerava capoeiristas, realizando uma repressão violenta dela. (SOARES, 1993, P. 354-355)

Em alguns raros momentos, a capoeira e seus praticantes ganharam destaque na sociedade, como quando os capoeiras são enviados para a Guerra do Paraguai (1864-1870) e se destacam em combate, retornando a seu país como membros do exército vitorioso, com destaque na sociedade (QUERINO, 1955, P.79-80).

Ainda com essa eventual "valorização" de alguns capoeiras por parte do Estado - traduzida como maior prestígio dos capoeiras entre membros da polícia e do exército - a capoeira permaneceu sendo perseguida e marginalizada após o fim da escravidão e da monarquia. Mais ainda, durante a Primeira República, a prática passa a ser proibida por lei (11 de Outubro de 1890, artigo 402 do código criminal da República), marcando o ápice da repressão contra a prática, em um período marcado 


\section{artigos}

\section{Pedro Gabriel Neves de Aquino}

por teorias raciais que buscavam determinar negros e outros grupos como um grande conjunto ligado a ideias de degeneração e atraso, inferiorizados perante a população branca.

Esses ideais foram difundidos principalmente entre os círculos das elites intelectuais do Brasil, com destaque para Silvio Romero e Nina Rodrigues, entre as décadas finais do século XIX e as primeiras do século XX. Assim:

"Raça surge como tema fundamental na análise desses autores e em suas considerações e diagnósticos sobre os destinos da nação" (SCHWARCZ, 2005, P.227).

Essas ideias raciais eram diversas entre si, vindo de diferentes autores e que foram interpretadas e adaptadas de diferentes maneiras pelos intelectuais brasileiros. É importante salientar que os intelectuais brasileiros não apenas consumiram as teorias europeias, mas sim as adaptavam para a nova situação na qual se encontravam, sendo mais real considerar as teorias aplicadas no país como teorias brasileiras, ainda que de inspiração original europeia.

De maneira geral, essas adaptações preservaram das teorias europeias a hierarquia entre raças (brancos superiores aos demais), mas teóricos influentes no meio como Sílvio Romero apontaram a importância do mestiço para a regeneração do país. Porém, elas concordavam em buscar, de alguma forma, em condenar o elemento africano e indígena da sociedade brasileira, marcando-os como grupos degenerados.

Essas ideias não ficaram restritas aos ciclos intelectuais do Brasil, mas se espalham entre políticos, marcando o pensamento de uma época que buscava higienizar as cidades, civilizar a sociedade e construir uma nova identidade que preservasse hierarquias do passado, como fica evidente abaixo: 


\section{artigos}

O papel dos cronistas brasileiros na transformação da imagem da capoeira no início do século XX (1900-1930)

“Em meio a um contexto caracterizado pelo enfraquecimento e final da escravidão, e ela realização de um novo projeto político para o país, as teorias raciais se apresentavam enquanto modelo teórico viável na justificação do complicado jogo de interesses que se montava." (SCHWARCZ, 2005, P. 21)

Esses pensamentos influenciaram fortemente a literatura da época, como as obras O Cortiço de Aluízio de Azevedo e Os Sertões de Euclides da Cunha, que expuseram estereótipos raciais e sociais de certas populações, inserindo esses tipos na memória comum daquela época. No caso do capoeira, se torna sinônimo de malandro, vadio, briguento, negro, como retratado na personagem Firmo em "O Cortiço". É importante perceber que estas são obras de circulação consideravelmente grande entre os círculos letrados do Brasil na época, tendo grande impacto na maneira como a sociedade se entendia. Assim, a construção dessas visões sobre os negros, mestiços e capoeiras forma a imagem que a sociedade teria sobre esses grupos, que passam a ser vistos apenas pela sua imagem negativamente construída. São representações marcantes que formam um tipo social marginal, que é negro, mestiço e capoeira e que, portanto, não teria espaço na nova sociedade que os intelectuais e o Estado buscavam construir (SCHWARCZ, 2005, P.266).

É nesse contexto de proibição e intensa perseguição contra a capoeira entre 1900 e 1930, tão marcado por essas ideias racistas e por estereótipos construídos sobre a capoeira e grupos sociais e raciais que a praticavam, que alguns intelectuais passam a defender uma valorização dessa prática entre os círculos letrados do país.

São intelectuais de todas as raças, praticantes da capoeira ou não, que promovem debates que valorizem a prática. Alguns argumentam associando a capoeira a um folclore nacional, como é o caso de Alexandre Melo Filho. Outros chegaram a defender o ensino da capoeira em escolas e quarteis, pensando-a em comparação com artes-marciais de outros países, como foi o caso de Coelho Neto. 


\section{artigos}

\section{Pedro Gabriel Neves de Aquino}

Mas a maioria propõe, diretamente ou indiretamente, que a capoeira seja valorizada enquanto esporte. Esse conjunto de intelectuais do período são classificados por Soares como cronistas e pioneiros, sendo os primeiros a escreverem sobre a capoeira de forma a positivá-la. Uma corrente da belle époque que teria grande influência nas discussões sobre a capoeira.

Além disso, outro grupo definido por Soares são os folcloristas, atuantes entre as décadas de 20 e 30, que apresentavam a valorização da capoeira ressaltando suas ligações culturais negras. Manuel Querino, autor que será tratado neste artigo se encaixa nesse grupo e disputou com os cronistas o entendimento sobre a capoeira.

Após a obra de Melo Filho "Festas e tradições populares do Brasil", de 1888, relançada em 1901, um número crescente de pensadores argumentou em prol da esportivização da capoeira, aparecendo em diversos formatos, como na forma de um artigo para revista, como transpareceu na Revista Kosmos em 1906, ou como um guia dos movimentos básicos da capoeira como o “Guia da Capoeira ou Gymnástica Nacional", de 1907.

Sendo assim, surge a questão, por que essa decisão de valorizar a capoeira como esporte? Essa escolha pela esportivização dialogava com as ideias de nacionalismo do período, podendo equiparar a "ginástica nacional brasileira" (capoeiragem) com práticas de países civilizados, servindo assim ao interesse de sistematizar a capoeira. Essa sistematização tornaria a prática mais vinculada a regras bem estabelecidas, pois uma prática esportiva pressupõe a existência de regras bem delimitadas (CALDAS, 2018, P.65). Isso restringiria seu caráter "das ruas" bem como as influências que a capoeira receberia, podendo a sistematização ser entendida como uma forma de controlar a capoeira. Assim, as propostas de esportização retiravam 


\section{artigos}

O papel dos cronistas brasileiros na transformação da imagem da capoeira no início do século XX (1900-1930) características cultuais negras da capoeira, implicando a sua descaracterização.

Dessa forma, começa a aparecer uma defesa da capoeira enquanto prática esportiva por parte de alguns intelectuais na cidade do Rio de Janeiro, por volta do ano de 1906, espalhando essa discussão pelo meio intelectual brasileiro, ligando-se a questões como a nacionalidade. Logo, surge um debate dentro dessa busca pela esportivização: Como a capoeira seria esportivizada? Preservaria sua herança e atributos afro-brasileiros ou apenas seus movimentos? O debate é marcado por obras sobre o tema, como "A Bahia de Outrora", de Manuel Querino, que destaca a necessidade dos elementos africanos para a capoeira.

Encontrando-se em um contexto de nacionalismo e construção de uma nacionalidade brasileira, as obras gravitam quase que naturalmente em torno de valorizar a capoeira como arte engrandecedora do Brasil, como parte dessa nacionalidade. Porém, como entender seus argumentos que giram em torno da construção de uma nacionalidade brasileira a qual a capoeira tinha que fazer parte, mas grande maioria dos autores nega ou ignora as raízes negras da prática? Pode-se inferir então que houve disputas pela preservação ou apagamento das origens negras, afro-brasileiras da capoeira que se buscava esportivizar, evidentes na literatura desses cronistas.

Há então uma busca e uma disputa pela construção dessa capoeira como prática nacional, se inserindo no contexto de construção da nacionalidade (nova, republicana, moderna), que era muito inspirada nos modelos das grandes nações europeias (França, Inglaterra comparação que o Brasil fazia) ou seja, há uma referência cultural exterior, europeia, e essas ideias do exterior tem sua atividade no modo de pensar brasileiro sobre essas questões, da sua cultura. 


\section{artigos}

\section{Pedro Gabriel Neves de Aquino}

Assim, aparecem questões tais quais como esses autores reconheceram práticas de origem ou herança negra como cultura ou esporte nacional? Ou buscaram deslegitimar os aspectos culturais negros da capoeira e seus praticantes? Isso também tem a ver com essa questão da mentalidade europeia que o Brasil tentava ter sobre si.

Esses debates construiriam, a partir de seus argumentos, narrativas que são disputadas pelos autores, por meio de suas obras e o impacto que elas tiveram na sociedade letrada da época. Dessa forma, a análise de diferentes obras de um recorte temporal busca explicar como se formou essa busca intelectual pela esportivização, quais foram seus argumentos base, como esses argumentos se desenvolveram, quais foram os debates que ocorreram e, mais importante, como esse debate influenciou a sociedade a ponto da capoeira vir a ser descriminalizada nos anos 30.

\section{Os primeiros argumentos dos intelectuais e esportivização da capoeira}

\section{Melo Morais Filho, 1888}

Partindo da primeira obra de grande impacto a valorizar a capoeira no Brasil no século XX, o livro de 1888, republicado em 1901, chamado “Festas e Tradições populares no Brasil", de Alexandre José de Melo Morais Filho, marcou uma geração de pensadores com sua argumentação e desenhou uma base argumentativa para escritores posteriores. Melo Morais foi um escritor baiano que viveu boa parte de sua vida no Rio de Janeiro, dedicando-se ao jornalismo, a poesia, a etnografia e ao folclorismo, havendo uma determinada intuição de nacionalismo em suas obras, tendo em alta escala o sentimento nacional (ROMERO, 1902, P. 607,621). Entretanto, ao contrário de Sílvio Romero (que fez o prefácio de seu livro), Morais reprovava a imigração europeia em larga escala e a europeização dos costumes defendidas pelas 


\section{artigos}

O papel dos cronistas brasileiros na transformação da imagem da capoeira no início do século XX (1900-1930) elites como a única forma de progredir (ASSUNÇÃO, 2005, P. 13), um posicionamento que nos ajuda a entender suas motivações ao valorizar a capoeira.

Para além da vida do autor, deve-se perceber como o tema da capoeira não era tratado pelos cronistas da época, muito menos valorizado. O livro de Morais Filho elabora uma série de argumentos, entre os quais a busca por uma valorização da prática, colocando-a num patamar de luta nacional do Brasil. construindo essa valorização da capoeira em alteridade com a valorização de práticas físicas europeias, como o boxe inglês e a savate francesa (ASSUNÇÃO, 2055, P.13), feito inédito para época, considerando o impacto que a obra teve nos círculos intelectuais. Observa-se assim um forte tom nacionalista ao construir seus argumentos, ainda que estejam muito vinculados a uma forma de pensar

Essas lutas, (...) concorrem para reunir mais um traço à fisionomia nacional (MORAIS FILHO, 2002, P.326)

Dessa forma, pode-se associar a valorização da capoeira com a construção da nacionalidade, além de outros argumentos presentes na obra. Segundo Letícia Vidor de Souza Reis:

Mello Moraes usa basicamente três argumentos, que seriam depois largamente empregados por outros que escreveram sobre a capoeira em princípios do século XX: a capoeira era um esporte (como jogo, ginástica, luta), era uma herança mestiça e era nacional(...)(REIS, 1993, P.233)

Ou seja, esse texto teria sido pioneiro na valorização da capoeira no século XX, com tom nacionalista, ordenador (um certo higienismo) para com a prática e ainda afirmaria que esta seria mestiça. Porém, deve-se atentar para o fato que o autor não nega a origem negra da capoeira, ainda que afirme que a capoeira de seu tempo é praticada por mestiços (pardos, mulatos e crioulos nas suas palavras). Logo no primeiro parágrafo do capítulo dedicado a capoeira diz: 


\section{artigos}

\section{Pedro Gabriel Neves de Aquino}

Entre as classe populares a dos capoeiras avultou sempre neste País, assinalando nos primeiros tempos costumes de uma torrente de imigração africana, e depois uma herança da mestiçagem e do conflito das raças.(MORAIS FILHO, 2002, P.325)

Assim, não se pode dizer que ele nega sua origem afro-brasileira. Na realidade, ele não trata da origem da prática, apenas cita, preferindo o trabalhar com outros temas, como a ampla difusão da capoeira entre os brasileiros, de capoeiras notáveis e de valores que ela possuía até os anos 1870. Sendo assim, por que não tratou dessa origem numa obra que visava enaltecer a prática?

Evidentemente que decidir "não falar" sobre determinado tema é mostrar alguma coisa, é mostrar que havia um preconceito sobre as práticas negras no período. Assim, ao não tratar sobre as origens da capoeira, o autor evidencia algo que não gostaria que aparecesse em destaque na obra: sua origem negra, escrava, sua herança afro-brasileira.

Pode-se tentar entender isso dado o contexto em que o autor escreve, marcado por teorias de superioridade racial. Apesar de destacar o mestiço enquanto principal praticante de capoeira, as teorias raciais já assinalavam que o país era composto majoritariamente por mestiços e, em adaptações brasileiras dessas teorias, como a feita por Silvio Romero, o mestiço não era necessariamente um empecilho ao desenvolvimento do país, estando na mestiçagem a saída para a situação do país (SCHWARCZ, 2005, P.126). Ou seja, valorizar a capoeira com uma visão nacionalista de país mestiço sem valorizar os negros era possível e foi o que Morais Filho fez. Dessa forma, apesar de ser um texto marcante na defesa da capoeira, é um texto muito atrelado à lógica racial de sua época.

Para além da questão racial, deve-se observar também como o autor faz uma argumentação romântica no sentido de valorizar os capoeiras do passado (antes de 


\section{artigos}

\section{O papel dos cronistas brasileiros na transformação da imagem da capoeira no} início do século XX (1900-1930)

1870, segundo o próprio) como valorosos, pessoas que respeitavam a autoridade do Estado, tinham família, não eram traíras etc, em clara contrapartida com os capoeiras de seu tempo, gatuno e assassinos. Assim, evocando um passado não tão distante, observa que:

Hoje que tudo se acha mudado, que se dizem capoeiras gatunos e assassinos, em que a bobagem dos duelos arma a popularidade ao desfrute, o jogo nacional da capoeiragem é apenas visto pelo que tem de mau e bárbaro, como se fosse menos mal e menos bárbaro do que as lutas da mesma natureza usadas por outros povos. (MORAIS FILHO, 2002, P.331)

Reforça assim o argumento introdutório do capítulo, defendendo a capoeira como uma prática de um povo, uma prática do Brasil, dizendo de maneira clara, mas não explícita que apesar de ter seu "lado ruim", que está sempre em destaque nos olhares da sociedade, a capoeira tem um lado bom que deve ser enxergado pela sociedade, tal qual ocorre com outras práticas nacionais no exterior, como o boxe. Utilizando da ironia, o autor estaria ainda fazendo crítica ao "espírito de vira-lata"1 dos brasileiros, um nacionalismo que não apoia práticas nacionais, sendo que esse seria o maior impedimento ao brasileiro valorizar nosso jogo nacional, nossa prática física nacional como outros povos "civilizados", segundo os termos da época, fazia.

Ademais, um outro grande destaque de sua obra é o pioneirismo no uso da palavra "jogo" para se referir à capoeira, termo esse que permite tratar da prática como um esporte, dotado de regras, organização, arbitragem etc. É provável que o termo já fosse utilizado antes por capoeiras, mas Melo Filho pode ser creditado por inserir esse termo, dotado de várias implicações implícitas, entre os cronistas de seu tempo, permitindo assim a seus contemporâneos buscarem uma esportivização

\footnotetext{
1 O conceito de "espírito de vira-lata" aparece apenas na metade do século XX, cunhado por Nelson Rodrigues, mas a postura do brasileiro de inferioridade diante de nações tidas como civilizadas ou grandiosas é antiga, como fica aparente no texto.
} 


\section{artigos}

\section{Pedro Gabriel Neves de Aquino}

posterior, já que seria um jogo, uma prática física passível de ser esportivizada. Apesar de usar o termo jogo, sua argumentação não buscou delimitar regras nem movimentos ou competitividade, algo necessário para que se considere a prática um esporte.

De todo modo, expostos os principais pontos sobre a capoeira em sua obra, deve-se entender que essa obra influenciou fortemente os cronistas no início do século XX, (mesclando a ideia de contemporaneidade com a ideia de luta nacional, dando ritmo às produções literárias sobre o assunto pelos próximos 40 anos (SOARES, 1993, P. 19), lançando as bases para uma defesa da capoeira enquanto prática nacional e, posteriormente, enquanto esporte. Assim, pode-se dizer que o “argumento central para a transformação da capoeira em patrimônio nacional teria vindo pela obra de Morais Filho 'Festas e Tradições populares no Brasil'”' (FONSECA, 2008, P.5-6).

Nesse sentido, apesar de Morais não ter buscado a esportivização da capoeira, colocando-a mais como uma prática física, um jogo e luta dos brasileiros que um esporte bem ordenado e regrado, sua argumentação de acordo com os ideais civilizatórios de sua época, muito marcados pelo nacionalismo e pelo cientificismo racial, acabaram criando as bases para alguns intelectuais de épocas posteriores construírem argumentos pró-esportivização da prática, marcando a época.

Um exemplo de como sua obra marcou o período para além dos círculos intelectuais do Rio de Janeiro, a Revista Kosmos, revista ilustrada das elites cariocas, de 1906 faz uso muito semelhante dos argumentos que Morais Filho. Assim, entendese que seu texto sobre a capoeira teve circulação entre círculos diversos das elites, tendo impacto na forma delas de entender a capoeira. 


\section{artigos}

\section{O papel dos cronistas brasileiros na transformação da imagem da capoeira no} início do século XX (1900-1930)

O artigo da revista, escrito por L.C. (provavelmente Lima Campos, escritor simbolista do período), traz a capoeira como "nossa" luta popular, comparando-a com lutas europeias etc. Apresenta também o argumento de que a capoeira seria mestiça, em concordância com o projeto nacional da época, de que o Brasil seria mestiço nesse momento para se tornar branco em algumas gerações para frente, atribuindo uma positividade ao elemento mestiço, aproximando-se assim do que advogavam na época os "teóricos do branqueamento" (REIS, 1993, P.233).

Evidentemente, a Revista Kosmos é uma publicação feita para as elites cariocas, portanto não é exagerado pensar que existe um certo romantismo sobre a capoeira, dotado de um discurso próprio para promovê-la nesse determinado ambiente. Isso fica evidente em uma passagem afirmando que a capoeira teria sido criada no período de independência do Brasil assim como o argumento de que seria uma criação carioca por excelência ${ }^{2}$, um argumento que agarra uma das teorias sobre a origem da prática, buscando atrair a atenção das elites do Rio, que quer construir a partir de si e de sua cidade uma noção de nacionalidade em um novo contexto republicano.

Essa certa liberdade para falar da capoeira e sua história se relaciona diretamente com a questão que, naquele momento de grande valor ao esporte e construção de um nacionalismo vibrante, os estudiosos e cronistas misturavam mito e realidade, ligando-se ao debate sobre nacionalidade e criação de uma identidade

\footnotetext{
$2 \mathrm{Na}$ época da revista, havia diferentes mitos e teorias sobre sua origem, como a suposta origem no Quilombo de Palmares, no período colonial, tese adotada e difundida por Aníbal Burlamaqui, autor contemporâneo que será tratado neste artigo, bem como a sua origem no Rio de Janeiro, adotada pela revista. Os debates sobre a origem da capoeira persistem até hoje, não havendo uma tese definitiva sobre a origem da capoeira. Para maiores informações sobre essas teorias, ver ASSUNÇÃO, "Capoeira The History of na Afro-brazilian martial art", Cap. 1
} 


\section{artigos}

\section{Pedro Gabriel Neves de Aquino}

nacional (LÍBANO, 1998, P.22). Assim, a capoeira envolvia-se como parte desse debate nacional da construção da nacionalidade, ligando-a a questões do centro político do país.

Há uma série de outros artigos entre os anos 1910 e 1920 sobre capoeira, nos mais diversos meios de publicação, como jornais diários, folhetins, revistas, evidenciando a difusão da prática em várias camadas da sociedade mas que, por falta de tempo hábil para as expor e discutir seus argumentos, não serão tratadas neste ar

Esta obra foi composta por um distinto oficial do exército brasileiro, mestre em todas as armas, professor de militares e habilíssimo na ginástica defensiva ou verdadeira arte do capoeira (ANÔNIMO, 1907, P.1)

Esse trecho apresenta alguns pontos a serem analisados. Primeiramente, a identidade do autor como sendo um oficial do Exército. Isso demonstra uma possível origem entre as elites ou pelo menos as classes intermediárias do período, explicitando como a capoeira estava disseminada ou se disseminando entre diferentes grupos econômicos e sociais no período.

Para além da identidade do autor, o trecho apresenta o ponto que a capoeira seria uma ginástica defensiva. Esse argumento infere que a capoeira "de verdade" é uma arte de defesa, não uma prática que de agressão, distanciando-a assim da imagem de criminosos e vadios a qual era tão associada. Assim, dá continuidade ao argumento de Melo Morais Filho, que afirma no último parágrafo dedicado a capoeira de sua obra:

A capoeiragem, como arte, como instrumento de defesa, é a luta própria do Brasil. (MORAIS FILHO, 2002, P.333)

Apesar desses aspectos analisados, esta obra é um guia para aqueles que 


\section{artigos}

O papel dos cronistas brasileiros na transformação da imagem da capoeira no início do século XX (1900-1930) buscam aprender a prática sendo assim, como já foi citado anteriormente, a primeira tentativa de sistematizar os movimentos da capoeira (ASSUNÇÃO, 2005, P.15-16). Assim, a maior parte dela é composta por descrições de movimentos do jogo, maneiras de executá-los e imagens ilustrando a explicações, sendo mais um guia (como o títuloh já diz) que um estudo sobre a prática. Essa construção de um texto na forma de um guia, já reflete por si só o entendimento da capoeira como prática esportiva, ignorando-se de alguma forma suas características histórico-culturais e, especialmente, ignorando a participação de negros e mestiços.

Porém, na introdução se realiza uma resumida explicação histórica sobre a ginástica nacional, ignorando, todavia, a origem da capoeira e os tipos raciais que a praticam, explicitando como a construção dessa imagem da prática nacional não necessariamente buscava valorizar ou integrar os grupos raciais "degenerados" que a praticava amplamente.

Além disso, sua sintética apresentação é uma narrativa bastante romantizada, colocando a capoeira de outrora com célebre, e que ela teria se degenerado aos longo dos anos pela ausência de mestres como os do passado. Uma visão bastante idealista de um passado que perseguia e punia a capoeiragem de forma bastante semelhante àquela da época em que o autor se encontra. Como já foi abordado, a mitificação de algumas narrativas sobre a capoeira era frequente, dado o interesse de fazer da prática parte da nacionalidade do país. A partir dessa narrativa romantizada mitificada, o texto valoriza a prática ligando-a ao nacionalismo, em comparação com atividades físicas nacionais do exterior, tal qual argumenta Melo Morais Filho, buscando assim elevar a capoeira como uma ginástica nacional para o Brasil, como fica evidente no trecho: 


\title{
artigos
}

\section{Pedro Gabriel Neves de Aquino}

\begin{abstract}
"Atualmente, o capoeira é representado pelo desgraçado vagabundo, trouxa, cachaça, gatuno, faquista ou navalhista, conhecido por alcunha que the garante a maior facilidade de entrada nos xadrezes policiais! Assim é o maior insulto para inutilizar um jovem é chamá-lo de capoeira. Foi, sem dúvida, nosso empenho levantar a Gymnástica Brasileira do abatimento em que jaz, nivelando-a como singularidade pátria, ao soco inglês, à savate francesa, à luta alemã, às corridas e jogos tão decantados em outros países. Nossa briosa mocidade hoje desconhece, pela maior parte, os trabalhos da arte antiga, e por isso nós resolvemos publicar o presente guia." (ANÔNIMO, 1907, P.2-3)
\end{abstract}

O trecho se inicia com a apresentação da capoeira degradada do tempo do autor, associada ao banditismo, que ele assume tentar elevar a um patamar igual ao de atividades físicas internacionais a partir da criação e publicação desse guia. Assim, entende-se claramente o objetivo desse guia: Elevar a capoeira a um patamar de ginástica nacional e remover sua associação com o banditismo e com a malandragem, fazendo isso sem reconhecer as origens da capoeira. Assim, tanto o texto apócrifo quanto Melo de Morais fazem argumentos que convergem no sentido de não reconhecerem sua origem negra.

Dessa forma, percebe-se que dentro do debate da capoeira, existe outro, centrado na questão da racialização da capoeira. Racialização aqui no sentido de que há um componente racial negro muito forte atrelado a prática, mas os intelectuais (de maneira geral) atuaram ativamente no sentido de apagar essa relação da capoeira com seu passado negro. Reconhecê-la como parte de uma cultura negra ou de origem negra seria problemático na época, uma vez que essa etnia era marginalizada e não era parte do projeto do Estado integrá-las. Dessa forma, a proposta de esportivizar a capoeira esquecendo seu elemento negro é, em grande medida, tirar ela de seus praticantes, inserindo a prática como parte da nação, não os negros e mestiços. É uma busca pelo controle das práticas afro no Brasil, bem como dos mestiços e negros que a praticavam. 


\section{artigos}

\section{O papel dos cronistas brasileiros na transformação da imagem da capoeira no}

início do século XX (1900-1930)

Coelho Neto, 1922

O argumento da esportivização ganha uma forma clara dessa maneira, buscando valorizar a capoeira por meio de um controle sobre ela. Esse argumento em prol da esportivização se tornou tão forte que, em 1910, Henrique Maximiano Coelho Neto teria pensado em apresentar ao Parlamento, junto a Luiz Murat e Germano Harlocher, um projeto instituindo a obrigatoriedade do ensino da capoeira em escolas e quartéis (IPHAN, P.18). O grupo teria desistido porque outros que ouviram a proposta a consideraram ridícula, supostamente por ser uma prática brasileira.

Isso nos mostra que havia pessoas do mais alto escalão intelectual interessadas na valorização e no regramento (leia-se controle) da prática. Coelho Neto chegou a organizar um movimento de oficialização do ensino de capoeira nas forças armadas (LIBERAC, 2001, P. 95). Afinal, Coelho Neto, além de intelectual, era também deputado na época em que pensou em realizar tal proposta. A defesa da capoeira enquanto esporte nacional havia penetrado assim os círculos de poder do país, local onde a prática poderia consolidar-se oficialmente como parte da nacionalidade.

É claro que, a recusa da proposta pelos colegas antes mesmo de ser feita publicamente mostra que a defesa da prática ser disseminada para as futuras gerações não era bem vista pela alta sociedade da época, ainda que houvesse defensores entre as elites. Assim:

Embora colocados como criminosos, os capoeiras tiveram uma recuperação social promovida pela "vertente nacionalista da belle époque", que buscava defender a capoeira como ginástica brasileira. Nesse sentido, Coelho Neto "representou o ponto alto da versão que defendia a transformação da capoeira em esporte nacional". Conforme Soares: "Coelho Neto não apenas realça as qualidades ginásticas da capoeira. Ele a celebra como a verdadeira educação física do Brasil, que deve ser ensinada nas escolas, quartéis, lares, em quaisquer lugares onde a instrução seja importante (IPHAN, 2005, P.18) 


\section{artigos}

\section{Pedro Gabriel Neves de Aquino}

Isso fica relatado na crônica "O Nosso Jogo" publicada em 1928 (nome bem sugestivo do que o autor quer), outra obra destinada a colocar a capoeira como um jogo, um esporte do povo brasileiro. Apesar da obra "O povo", que inclui o que Coelho Neto fala sobre capoeira, ser publicada como livro em 1928, a defesa da capoeira pelo autor já aparece escrita em 1922, em um romance chamado O Bazar.

Este foi mais um texto que estava atrelado a ideia de esportivizar a capoeira, usando pra isso um discurso romântico e idealizado de seu passado, mas que busca fazer essa esportivização sem falar da origem negra da capoeira, tal qual ocorre na Revista Kosmos e no livro de Morais Filho. Dessa forma, entende-se que prevalecia um discurso bem alinhado com as ideias racialistas de seu tempo, tratando a capoeira com caráter nacional, mas ignorando a cor dos brasileiros que a fizeram e a praticavam. Porém esse discurso não passou sem ser contestado e colocado em debate.

\section{Os intelectuais e a herança negra da capoeira em destaque}

\section{Manuel Querino, 1916}

Apesar de Morais Filho apresentar questões raciais e a revista Kosmos tocar nesse assunto, ambos ignoram o elemento negro da capoeira e estão consideravelmente apoiados nas ideias de Sílvio Romero e Nina Rodrigues, constituindo mais uma continuidade desse pensamento que uma contestação dele. 0 mesmo aconteceu com o Guia do Capoeira e a obra de Coelho Neto, que ou ignoravam ou negavam a herança negra dessa prática, demonstrando assim um não reconhecimento da racialidade presente na capoeira, reconhecendo-a somente no que tange a apontar vadios e malandros que praticavam a arte. Pelo fato da esportivização da capoeira ter se tornado um tema bastante discutido nos anos 10 e 


\section{artigos}

O papel dos cronistas brasileiros na transformação da imagem da capoeira no início do século XX (1900-1930) 20, não é surpreendente que esse predomínio da negação da herança afro viesse a ser contestada e colocada em debate. E foi exatamente isso que Manuel Querino fez em sua obra "A Bahia de Outrora" de 1916.

Querino foi um intelectual negro, nascido na Bahia, que se opunha aos ideais raciais de seu tempo (ASSUNÇÃO, 2005, P.20). Mais que apenas se opor, Querino foi um autor dotado de uma ousadia ímpar, indo mais além que apenas se opor às ideias do racismo científico, mas chegando a afirmar que o elemento negro africano foi o fator determinante para a civilização do país. Assim, ele está entre os primeiros escritores da Primeira República Brasileira a buscar valorizar os negros no Brasil, em diversos aspectos da sociedade.

Isso fica evidente na sua obra A Bahia de Outrora, de 1916, na qual, dentre uma série de outras questões, Querino está afirmando a presença e origem negra na capoeira. Mais que apenas isso, ele tentou elevar a capoeira dos negros ao patamar de destaque para a nação, colocando negros e capoeiras como grupos a serem símbolos de valor e bravura. Isso fica evidente na seguinte passagem:

Por ocasião da guerra com o Paraguai, o governo da então Província fez seguir bom número de capoeiras; muitos por livre e espontânea vontade (...) E a prova desse aproveitamento está no brilhante feito darmas praticado pelas companhias de Zuavos Baianos, no assalto ao forte Curuzú, debandando os paraguaios, onde galhardamente fincaram o pavilhão nacional. (QUERINO, 1955, P.78).

Ao mesmo tempo que realizava tal valorização, destacando-os no cenário de guerra, atribuindo assim valor para a nação, Querino apontava como os capoeiras constituíam um elemento perigoso em certo período, tornando-se necessário que o governo estabelecesse penas e castigos relativos a sua prática (QUERINO, 1955, P.80). Isso mostra que apesar de sua defesa da prática cultural negra que era a capoeira, ele 


\section{artigos}

\section{Pedro Gabriel Neves de Aquino}

estava alinhado com discursos da época que associavam os capoeiras com a criminalidade.

Evidentemente que o autor procurava dar às pessoas do povo destaque em eventos da história nacional (DANTAS, 2015, P.70-71), leia-se aqui, destaque para negros e pardos, mas isso não excluiu sua percepção sobre o tipo social do capoeira. Querino positivou a prática da capoeira, não necessariamente seus praticantes.

Ainda assim, a obra coloca a prática enquanto valorosa e enquanto atividade física e cultural, dotada de história, música e tradições. Nesse sentido, apresenta cantigas que eram cantadas junto ao jogo, destacando que apesar de alguns jogarem capoeira como um esporte, outros faziam dela sua profissão. Com isso o autor defende a permanência de uma capoeira "tradicional", vinculada a essa herança cultural afro-brasileira, ainda que haja pessoas que a pratiquem como esporte, entendendo a prática como uma arte afro-brasileira, maior que uma mera atividade física.

É claro que, ao disputar a forma de valorização da capoeira a partir de sua obra, Querino também se insere no debate maior sobre esportivização da prática. Por exemplo, quando utiliza do termo "brinquedo" e "jogo" para se referir a capoeira de seu tempo, permite-nos inferir uma característica lúdica dentro da capoeira heroica que ele buscou retratar. Sendo lúdica, é passível de ser regrada e praticada como exercício físico, tal qual ele expõe que:

“certas pessoas da representação social praticam o exercício como um meio de desenvolvimento e de educação física, como o futebol e outros gêneros de esporte" (QUERINO, 1955, P.74).

Ainda assim, seus argumentos nessa obra formam uma disputa pela capoeira que se buscava esportivizar. Seria ela uma prática física nacional que reconhecia sua 


\section{artigos}

O papel dos cronistas brasileiros na transformação da imagem da capoeira no início do século XX (1900-1930) origem negra, e assim, reconhecia no negro uma das bases para a nação e sua nacionalidade? Ou seria uma prática despojada de herança negra, se tornando mais um esporte imitativo dos europeus, sem musicalidade, sem tradições, sem história? Apesar de não propor sua esportivização, Querino tem um argumento claro de valorização da prática afro-brasileira, reconhecendo-a como arte nacional, de origem negra escrava e apresentando sua difusão pelas diversas camadas da sociedade. Nesse sentido, faz parte de um bloco de intelectuais definidos por Soares como folcloristas, que tinham uma tônica argumentativa pela valorização da capoeira como cultura popular (SOARES, 1993, P.16), estando menos focados na sua esportização que os chamados cronistas e pioneiros abordados anteriormente e mais focados na sua preservação e difusão enquanto cultura popular, com suas características culturais respeitadas.

Os escritos de Querino teriam impacto no meio intelectual negro. Observa-se que o folclorista Edison Carneiro é muito influenciado por sua obra e faria, poucos anos depois, um percurso semelhante, buscando destacar o papel dos negros na cultura e na construção da sociedade brasileira. Isso nos mostra que essa valorização da capoeira foi disputada por diferentes debates e diferentes entendimentos do que a sociedade brasileira era e do que deveria ser. Assim, podemos entender o processo de valorização e esportivização da capoeira como uma disputa, nesse meio intelectual, pela construção da nacionalidade.

Dessa maneira, Querino se insere como um cronista que defendeu o valor da capoeira enquanto prática física, sempre atrelada as suas tradições e heranças negras brasileiras. Sua defesa foi extremamente contrária aos ideais raciais da época e bastante ousada no sentido de questionar abertamente a forma que a elite intelectual tinha de entender a sociedade brasileira. Realizou assim obras muito 


\section{artigos}

\section{Pedro Gabriel Neves de Aquino}

assertivas, participou de congressos Afro-Brasileiros, criticou Nina Rodrigues e suas ideias, mas ainda assim não teve um impacto na sociedade como um todo, tendo impactado os círculos intelectuais, principalmente intelectuais negros de sua época e posteriores, como o já citado Edison Carneiro.

Apesar de sua notória valorização do negro e da capoeira como arte negra bem como seus posicionamentos fortemente contrários aos ideais da época, Manuel Querino não foi o único a reconhecer a origem negra da capoeira nem o que teve maior impacto.

\section{Anníbal Burlamaqui (Zuma), 1928}

Coube a um escritor posterior a Querino o reconhecimento da origem negra da capoeira, inserida em um projeto de esportivização muito bem definido, que teve algum grau de sucesso: Annibal Burlamaqui. Conhecido pelo apelido Zuma, Burlamaqui foi um mestre de capoeira da década de 20 e 30, além de escritor e político, que propôs uma metodização muito detalhada da capoeira em sua obra “Gymnástica Nacional (Capoeiragem) Methodizada e Regrada”, de 1928.

O títuloh já diz bastante sobre o que a obra pretendeu ser, mostrando que era uma obra que buscava colocar regras e métodos de aprendizagem sobre a prática, ou seja, transformá-la em esporte. Assim, segundo Alan Caldas, entende-se que Burlamaqui "projetou a capoeira como um esporte nacional que era o resultado da evolução da capoeira. Em seu livro “Gymnástica Nacional (Capoeiragem) Methodizada e Regrada" (1928), o autor desenvolve a ideia de que a capoeira teria surgido pela imitação dos movimentos dos animais, depois teria sido arma de libertação dos escravos para, enfim, tornar-se um esporte nacional (CALDAS, 2018, P.66). 


\section{artigos}

\section{O papel dos cronistas brasileiros na transformação da imagem da capoeira no}

início do século XX (1900-1930)

Dessa forma fica exposto que Zuma reconhecia a herança negra da capoeira, e partia desse entendimento para organizar ela enquanto esporte. O preço dessa proposta era ignorar completamente as origens afro-brasileiras da arte e o contexto cultural de sua prática (ASSUNÇÃO, 2013, P.6). Dessa forma, coloca a capoeira como uma prática afro-brasileira. Discussões sobre a origem da capoeira permanecem até a atualidade, porém, há uma concordância de que a capoeira é uma prática criada pelos negros, escravizados no Brasil, argumento difundido amplamente com a obra de Burlamaqui.

Para além da herança negra, Zuma buscou regulamentar a prática a partir de um ordenamento amplo sobre os movimentos possíveis, sendo a maior parte de sua obra um guia de golpes e métodos para o ensino e aprendizagem da arte, delimitando assim o espaço da prática.

Seu projeto pela esportivização é o primeiro a apresentar uma proposta ampla de como torná-la efetivamente esporte. Assim, surge a questão, por que os outros tantos argumentos anteriores não fizeram propostas firmes quanto a isso? Isso teria se dado devido ao momento de renovação da cultura nacional, pelo menos entre as elites intelectuais, inaugurado pela Semana de 1922. Segundo Matthias Assunção:

O novo momento provavelmente teve impacto no meio intelectual. Somente durante o período de intensa renovação cultural inaugurado pela "Semana de Arte Moderna", de 1922, que essas atitudes começaram a ser canalizadas em propostas mais tangíveis. (ASSUNÇÃO, 2005, P.16-17)

Mais que realizar um projeto tangível, Zuma "propõe uma maneira clara de redimir a capoeira de sua posição marginalizada, de sua associação com vadios e criminosos, que seria torná-la igual a outros esportes ocidentais e orientais" (ASSUNÇÃO, 2005, P.128), marcando assim um ápice dos ideais de esportivização. 


\section{artigos}

\section{Pedro Gabriel Neves de Aquino}

A grande questão é que para realizar tal esportivização ela apagou os elementos africanos dela. Dito isso, transparece uma certa contradição em sua obra, porque ao mesmo tempo que reconhece a origem negra e escrava da capoeira, a esportivização da capoeira que ele propõe não considera os elementos musicais da capoeira, suas canções e instrumentos, que contam a sua história, apesar de reconhecer suas origens. Deixa a capoeira apenas com os movimentos do corpo, sem seu caráter cultural. Esse foi o esporte que ele propôs. Mas teria sido por meio dessa esportivização, que sacrifica as práticas culturais afro-brasileiras, que Zuma propõe uma regeneração do capoeira e da capoeira. É a partir da remoção desses elementos e do consequente controle da prática que a capoeira seria aceita na população no geral e se tornaria prática nacional.

Não foi uma abordagem inédita, mas foi além de velhos argumentos, como o de Morais Filho, colocando a capoeira não como uma prática comparável às do exterior, mas sim em prática esportiva igual às de outros países. Sua proposta é essencialmente uma continuidade mais organizada e aprofundada das discussões anteriores, feitas por Coelho Neto e Morais Filho, assim como seus movimentos são uma continuidade mais ampla e bem descrita que o texto apócrifo de 1907 (o primeiro guia do capoeira), constituindo assim o primeiro código desportivo da capoeira.

Enfim, talvez a coisa mais relevante sobre a obra de Zuma tenha sido seu impacto na sociedade. Burlamaqui aparece no cenário carioca como o primeiro capoeira desportista (PIRES, 2001, P. 99), mudando a percepção das classes altas sobre a prática. Além disso, teria influenciado Mestre Bimba (o movimento da queixada existente no seu livro aparece novamente em Bimba), responsável pela organização da primeira academia de luta regional baiana (Capoeira) em Salvador, em 


\section{artigos}

O papel dos cronistas brasileiros na transformação da imagem da capoeira no início do século XX (1900-1930) 1934.

A obra de Zuma teria ainda influenciado também outras figuras que participariam diretamente do centro de poder político do Brasil, como Inezil Penna Marinho, membro destacado da DEF (Difusão de Educação Física do governo de Getúlio Vargas), que incorporaria nos anos 40 a defesa da esportivização e obrigatoriedade do ensino da capoeira como prática ginástica nacional, baseado amplamente na obra de Burlamaqui, assim como realiza essa proposta com grande suporte na obra de Querino, reconhecendo a origem negra da capoeira, sua musicalidade e tradições (ASSUNÇÃO, 2005, P.19).

Assim, a partir do impacto de sua obra em grandes nomes da capoeira e de influência política, essa visão de uma capoeira esporte e de origem negra, escrava, que Burlamaqui construiu com base em outros debates anteriores, se espalharia pelo Brasil como parte da nacionalidade.

\section{Considerações finais}

Com isso, a partir da análise realizada das obras e argumentos de diversos intelectuais brasileiros do início do século $X X$, percebe-se que a construção de uma imagem positiva da capoeira, inclusive como prática nacional, começa a ser buscado desde pelo menos 1888, com a obra de Melo Filho, que compara a capoeira com outras práticas físicas europeias. Porém, somente quando se insere o argumento de que a capoeira poderia ser a ginástica nacional, o esporte nacional, é que a perspectiva geral sobre a prática começaria a mudar, como fica evidenciado pela obra de Burlamaqui.

Os primeiros autores, apesar de mostrarem que a capoeira era valorosa, não 


\section{artigos}

\section{Pedro Gabriel Neves de Aquino}

afirmavam que ela estaria por isso "redimida" de sua degeneração social racial. Melo Morais e Coelho Neto somente deploravam a "degeneração" da capoeira e consideravam que havia possibilidade de redenção de seus "vícios", porém não fizeram nenhum plano concreto de como realizá-la (ASSUNÇÃO, 2005, P.16-17). O Guia do Capoeira ou Ginástica Nacional de 1907 preferiu ignorar a questão da herança cultural negra e da raça de seus praticantes, ignorando também sua musicalidade, seu caráter folclórico, suas tradições. Buscou reduzi-la a apenas um emaranhado de movimentos, algo que poderia ser controlado e ensinado de acordo com seu projeto.

Assim, manifestou-se o debate sobre por que esportivizar? Não poderia a capoeira ter sido valorizada pela música, como tradição folclórica? Como explicado na primeira parte do artigo, esportes estavam em um momento de valorização no mundo. Eram práticas que podiam ser dotadas de caráter nacionalista e engrandecer a nação perante outras. Além disso, esporte é algo com regras e competições bem estabelecidas, controlado em um certo sentido. Colocar a capoeira como esporte nacional pode ser entendido, portanto, como uma forma de mostrar que os argumentos racialistas de que negros e mestiços, principais componentes dos praticantes de capoeira, não eram degenerados, mas sim parte da nação.

O argumento de que capoeira somente era vista com negatividade pelos brasileiros enquanto outras práticas estrangeiras, tão violentas quanto e praticadas pelas mesmas camadas subalternas da sociedade, são celebradas nos remete ao preconceito que o brasileiro tinha e tem sobre suas próprias práticas, uma "autossabotagem nacional". Afinal, o que diferenciava a capoeira do boxe era um apelo do estado e da sociedade em transformar aquela prática em algo de valor. Nesse quesito a influência dos intelectuais em produzirem argumentos que se 


\section{artigos}

O papel dos cronistas brasileiros na transformação da imagem da capoeira no início do século XX (1900-1930) espalharam pela sociedade foi primorosa, valorizando a capoeira enquanto parte da nacionalidade brasileira enquanto um esporte. A esportivização da capoeira teria sido então uma forma encontrada de conciliar o interesse nacional de construir uma identidade brasileira com a valorização da capoeira perante a sociedade.

É claro que houveram disputas, dentro dessa movimentação intelectual pela esportivização, pela preservação ou apagamento das tradições e origens negras da capoeira. Essas disputas ficam evidentes na literatura de Manuel Querino, que lança uma série de argumentos pela esportivização reconhecendo sua origem e herança negra, assim como no Guia apócrifo de 1907, que ignora completamente o elemento africano da prática de maneira consciente.

Além disso, os intelectuais fizeram uma reformulação da imagem no passado para construir uma nova imagem no presente (ASSUNÇÃO, P.19). Querino é um exemplo desse percurso que buscou valorizar a prática a partir da experiência de capoeiras que foram para a Guerra do Paraguai e retornaram como heróis.

É importante ressaltar que o esforço dos capoeiras para serem valorizados nas ruas também existiu, como a existência e relevância de Mestre Bimba atesta, mas teria sido nas letras, na escrita dos intelectuais que essa prática passa a ser entendida como algo de valor por grupos sociais distintos, mudando a perspectiva das classe altas, dos detentores do poder no Brasil, pelo menos nesses 30 anos iniciais do século $\mathrm{XX}$.

Ademais, esses autores teriam tido grande influência em intelectuais posteriores, como Edison Carneiro, que juntamente com Gilberto Freyre, discutem questões relativas à formação da nacionalidade brasileira, a racialização de certos grupos, marginalização, e a capoeira enquanto parte desse todo. 


\title{
artigos
}

\section{Pedro Gabriel Neves de Aquino}

Por fim:

\begin{abstract}
"A capoeira continua um popular exercício de agilidade na Bahia e Rio de Janeiro, prática realmente despojada do caráter agressivo de outrora. Sempre executada ao som dos berimbaus, urucungos ritmadores, monocórdios, a demonstração tem um aspecto ginastico, sugestivo pela precisai dos golpes, dando a imagem real de uma dana poderosa de força disciplinada e de elegância natural.

Está na classe das demonstrações desportivas.
\end{abstract}

O capoeira desapareceu, mas a Capoeira ficou".

(CASCUDO, P.189)

O trecho escrito por Câmara Cascudo mais de 30 anos após o período analisado, nos mostra que a musicalidade, a herança cultural negra da capoeira prevaleceu, mesmo com projetos de esportivização que não prezavam por isso. Agora o tipo-social do capoeira foi sendo desintegrado durante a Primeira República, tanto pela repressão, quanto pela aceitação da capoeira como prática esportiva, na qual diversas classes sociais participam, esportivização promovida amplamente pelos cronistas.

Assim, entre disputas de narrativa, disputas sobre o reconhecimento e valorização da origem negra da capoeira, assim como as disputas sobre o reconhecimento e valorização dos negros e mestiços que praticavam e desenvolviam a capoeira, os intelectuais do início do século XX que abordaram a capoeira nesse período foram responsáveis por consideráveis mudanças no entendimento da capoeira perante a sociedade. Influenciaram nomes da política e da capoeira, que manifestariam essa influência nos anos posteriores.

Mesmo com disputas argumentativas e aparentes contradições, esses autores tiveram grande importância no enfrentamento de uma lógica vigente que condenava a capoeira a ser uma arte dos marginalizados, a ser perseguida. A capoeira que 


\section{artigos}

O papel dos cronistas brasileiros na transformação da imagem da capoeira no início do século XX (1900-1930)

muitos defenderam era uma capoeira muito diferente daquela praticada nas ruas das cidades brasileiras do início do século XX, mas ainda era capoeira. Assim, deve-se reconhecer o mérito dos autores em buscarem subverter a ordem entre seus leitores no meio intelectual e letrado, transformando a prática em algo aprazível para as elites e classes médias, algo que dialogasse com a nacionalidade nova do Brasil e que fosse aceito pela sociedade no geral. Assim como também deve-se reconhecer seu diálogo com o pensamento racial de seu tempo, uma vez que prezaram pela valorização da prática, não dos grupos racializados que a praticavam.

\section{Referências Bibliográficas}

ANÔNIMO. Guia do Capoeira ou Gymnástica Nacional. Rio de Janeiro: Livraria Nacional. 1907.

ASSUNÇÃO, Matthias Rohring. Capoeira: The History of an Afro-Brazilian Martial Art. Nova lorque: Routledge, 2005.

Idem. Ringue ou academia? A emergência dos estilos modernos da capoeira e seu contexto global. Rio de Janeiro: História Ciência, Saúde - Manguinhos. 2013.

CALDAS, ALAN. Valentia e Linhagem: Uma História da Capoeira. Curitiba: Appris. 2018.

CASCUDO, Luís da Câmara. Folclore do Brasil (pesquisas e notas). São Paulo/Rio de Janeiro: Editora Fundo de Cultura. 1967.

FONSECA, Vivian Luiz. A capoeira contemporânea: Antigas questões, novos desafios. Rio de Janeiro: CPDOC FGV, Revista de História do Esporte, volume 1, número 1, junho de 2008.

IPHAN. Dossiê Inventário para registro e salvaguarda da capoeira como patrimônio cultural do Brasil. Brasília, 2007.

MORAIS FILHO, Alexandre José de Melo. Festas e Tradições populares no Brasil. Brasília: Editora Senado Federal. 2002. 


\section{artigos}

\section{Pedro Gabriel Neves de Aquino}

PIRES, Antônio Liberac Cardosos Simões. Movimento das cultura afo-brasileira: A formação histórica da capoeira contemporânea. Tese de Doutorado. Campinas: Unicamp, 2001.

REIS, Letícia Vidor de Souza. A capoeira: de doença mental à "Gymnástica nacional". São Paulo: Revista de História nº129-131, P.221-235, 1993.

ROMERO, Sílvio. História da Literatura Brasileira - Segundo Tomo. Rio de Janeiro: Editora H. Garnier. 1903.

SOARES, Carlos Eugênio Líbano. A Capoeira Escrava e outras tradições no Rio de Janeiro (1808-1850). Tese de Doutorado. Campinas: Unicamp, 1998.

Idem. A negrada instituição: Os capoeiras no Rio de Janeiro (1850-1890). Tese de Mestrado. Campinas: Unicamp, 1993.

SCHWARCZ, Lilia. O Espetáculo das Raças: Cientistas, instituições e questão racial no Brasil do século XIX. São Paulo: Companhia das Letras. 2005.

QUERINO, Manuel. A Bahia de Outrora. Salvador: Livraria do Progresso. 1955. 